Research Article

\title{
Knowledge and Practices towards Prevention and Early Detection of Chronic Kidney Disease and Associated Factors among Hypertensive Patients in Gondar Town, North West Ethiopia
}

\author{
Daniel Asmelash (D), Elias Chane, ${ }^{2}$ Getahun Desalegn, ${ }^{2}$ Sewmalet Assefa, ${ }^{2}$ \\ Getie lake Aynalem ${ }_{(D}{ }^{3}$ and Alebachew Fasil ${ }^{1}{ }^{1}$ \\ ${ }^{1}$ Department of Clinical Chemistry, School of Biomedical and Laboratory Sciences, College of Medicine and Health Sciences, \\ University of Gondar, P.O. Box 196, Gondar, Ethiopia \\ ${ }^{2}$ Department of Medical Laboratory Sciences, School of Biomedical and Laboratory Sciences, \\ College of Medicine and Health Sciences, University of Gondar, Gondar, Ethiopia \\ ${ }^{3}$ School of Midwifery, College of Medicine and Health Sciences, University of Gondar, Gondar, Ethiopia
}

Correspondence should be addressed to Daniel Asmelash; daniel.asmelash111@gmail.com

Received 5 February 2020; Revised 24 June 2020; Accepted 24 July 2020; Published 7 August 2020

Academic Editor: Tomohiro Katsuya

Copyright (c) 2020 Daniel Asmelash et al. This is an open access article distributed under the Creative Commons Attribution License, which permits unrestricted use, distribution, and reproduction in any medium, provided the original work is properly cited.

\begin{abstract}
Background. Chronic kidney disease is a global health problem with serious adverse effects, including kidney failure, cardiovascular disease, and premature death. Improving awareness and practice on the impact, prevention, and early detection of chronic kidney disease will reduce the significant economic and public health burden. Methods. A cross-sectional study was conducted to determine knowledge and practice towards prevention and early detection of chronic kidney disease and its associated factors among hypertensive patients in Gondar town in 2019. The study included hypertensive patients visiting health institutions from February to March 2019. Data was collected using a semistructured questionnaire and individuals who fulfilled our inclusion criteria were selected using a systemic random sampling technique. Epi Info software version 7 was used for data entry, and SPSS version 20 was used for descriptive and logistic regression analysis. Result. Out of a total of 442 participants, 434 completed the questionnaire, with a response rate of $98.1 \%$. Of the total, 298 (68.7\%) had good knowledge of chronic kidney disease with a mean knowledge score of $8.78 \pm 2.80$ and 210 (48.4\%) had good practice with mean practice score of $6.58 \pm 1.61$. Educational status, residence, and duration of hypertension were significantly associated with the knowledge and practice scores of the participants in the multivariate logistic regression analysis. Conclusion. More than half of the participants had good knowledge about chronic kidney disease and its risk factors. However, the level of preventive practice among participants was low. The educational status, residence, and duration of hypertension were significantly associated variables with knowledge and practice scores in multivariate logistic regression.
\end{abstract}

\section{Introduction}

Chronic kidney disease (CKD) is a global health problem with an increasing incidence rate, poor outcomes, and high treatment and management cost [1]. CKD is increasing worldwide at an annual growth rate of $8 \%$. There are regional differences in the disease epidemiology; the prevalence of
CKD in developing countries is higher than in the developed world [2]. The Global Burden of Disease (GBD), 2015, study estimated that 1.2 million deaths from cardiovascular diseases were directly attributable to reduced glomerular filtration rates (GFR) [3].

CKD can be categorized into five stages, ranging from mild stage-1 disease to severe end-stage renal disease 
(ESRD), stage 5 [4]. The majority of individuals with CKD are living in low- and middle-income countries. In addition, findings also indicate that women have a higher prevalence of CKD and the prevalence has steadily increased with age in high-income and low-income countries [5].

There are factors that directly cause kidney damage, increase susceptibility to CKD, worsen kidney damage, and result in a faster decline in kidney function. These factors include older age, family history, diabetes mellitus (DM), higher blood pressure, poor glycemic control in diabetes, and smoking [6]. Moreover, the prevalence of CKD increases with increasing age and exceeds $20 \%$ in individuals over 60 years of age and 35\% in individuals over 70 years of age [6]. Recent data showed that hypertension and DM are the two major causes of kidney disease worldwide, including both developing and developed countries [7].

Hypertension is the second major cause of ESRD besides DM. Nearly, one billion people worldwide have high blood pressure and that number is expected to increase to 1.56 billion people by 2025 . The prevalence of hypertension is predicted to increase by $24 \%$ and $80 \%$ in developed and developing countries, respectively [8]. Hypertensive patients had a far greater prevalence of CKD (26\%) compared to those without the disease $(8 \%)[9,10]$.

The outcomes of CKD are not only limited to kidney failure (KF) or ESRD but also complications of decreased kidney function or low GFR rate and cardiovascular disease. Recent evidence indicates that early detection and treatment can prevent or delay some of these adverse outcomes [1]. No national studies have been conducted on the prevalence of hypertension in Ethiopia, yet the reported rate of hypertension in some studies varied from $20 \%$ to $30 \%$ [11].

Increasing awareness among individuals at risk of developing $\mathrm{CKD}$, including those hypertensive patients, about the impact of CKD and its effective management could reduce the significant economic and public health burdens. Knowledge of CKD and risk factors enhances the perception of high risk and increases health-seeking behavior [12]. The implementation of acquired knowledge for prevention and control of CKD, supported by a combination of modern technology and healthcare support for those who are at risk of CKD, will result in good practice [13].

Despite the fact that CKD causes numerous public health problems, there are only a few studies in knowledge and practices towards CKD among high risk individuals, such as hypertensive patients. Thus, there is a need to assess the awareness and preventive practice towards CKD to make an effective intervention plan and to propose an effective policy related for high risk individuals. The aim of the study was to assess the knowledge and preventive practice of hypertensive patients towards CKD and to determine the clinical and sociodemographic factors which may affect the knowledge and practice towards CKD.

\section{Methods}

2.1. Study Setting and Design. The study was conducted at Maraki Health Center, Azezo Health Center, and University of Gondar Referral Hospital Chronic Disease Clinic in
Gondar town. The institutions are located in the Amhara regional state, which is about 741 kilometers northwest of Addis Ababa, capital city of Ethiopia. Cross-sectional study was conducted to determine the level of knowledge and practice towards $\mathrm{CKD}$ and its associated factors among hypertensive patients from February 1 to March 30, 2019.

2.2. Population Characteristics. All hypertensive patients followed up at University of Gondar Hospital and Maraki and Azezo Health Center at the time of data collection, who were willing to participate in the study, voluntary provide their sociodemographic information, and were willing to answer questions about knowledge and practice related to CKD were included. Hypertensive patients with present CKD, patients with mental health problems, hearing impairments, or any other critical health problems, and those who are unable to provide the appropriate information were excluded.

2.3. Sample Size and Sampling Technique. The sample size was determined by using a single population proportion formula. The proportion was taken at 50\%, with $95 \%$ of confidence intervals (CI) and $5 \%$ of margin error; $n=z^{2} \mathrm{p}(1-p) / \mathrm{w} 2$, where $n=$ sample size, $p=$ proportion, $w=$ margin error, $z=1.96$ confidence level, and $n=1.96^{2}(0.5(1-0.5)) /(0.05)(0.05)=384$. By considering the $15 \%$ nonresponse rate, the sample size was 442 , and a simple random sampling technique was used to select study participants.

Three health facilities, Azezo Health Center, Maraki Health Center, and University of Gondar Specialized Hospital Chronic Clinic, were selected from a total of 11 health institutions identified in Gondar Town using random sampling techniques. Probability proportional to sample size was used to select participants in the health institutions, and every $3^{\text {rd }}$ participant of the study was involved in the study using systematic random sampling techniques from the selected institutions.

2.4. Study Instrument. The study instrument was an adaptation of the measures developed in a study done in Palestine and the relevant $\mathrm{CKD}$ related scientific literature was reviewed, and, finally, 25 questions were generated to assess knowledge and practice towards CKD [14].

The reliability of the questionnaire was assessed by conducting a pilot study. The prepared questions were pretested to ensure they are eligible and to avoid any confusion regarding the understanding of the questionnaire and the questionnaire was modified based on feedback from the pilot study. A previously developed questionnaire was modified to suit the study setting, the questionnaire was reevaluated after the first pilot study on 11 hypertensive patients, and a further pilot study was performed in another 11 hypertensive patients.

Face validity was performed in hypertensive patients to evaluate the comprehension of the layperson towards understanding of the questionnaire and to assess how 
important it was to target study participants. Participants were asked to analyze each item of the questionnaire following the open-ended discussion and their diverse responses and interpretation of the different issues; how it was presented and the lack of ambiguity were evaluated. A revised version of the questionnaire was developed on the basis of the face-validation results, which helped to differentiate knowledge and practice items to CKD that were relevant to the study participants. The final draft questionnaire included 3 parts and 34 items (9 items on sociodemographic characteristics, 14 items on knowledge, and 11 items on practice).

Participants who responded correctly to $50 \%$ or more of knowledge and practice questions were considered as having adequate knowledge about CKD, whereas those who scored $<50 \%$ were considered as having poor knowledge and practice towards CKD. Each response was scored as "1" for correct response/practices and "0" for incorrect responses/ practices. The knowledge and practice scores of individuals were calculated and summed up to give the total knowledge and practice score.

Data were collected by trained and experienced clinical nurse data collectors through face-to-face interviews using the constructed questionnaires. The questionnaire was first prepared in English and then translated into the local Amharic language with the assistance of a language expert. The questionnaire consisted of three portions: the first portion deals with sociodemographic characteristics; the remaining two portions contain questions on the assessment of participants' knowledge and preventive practice. Data were collected from the selected hypertensive patients by a trained data collector through systematic random sampling and every $3^{\text {rd }}$ participant who fulfilled the inclusion criteria was asked to participate after the aim of the study was briefly explained. The collected data was checked daily for consistency, accuracy, and preventing any bias.

2.5. Statistical Analysis. The data were entered by Epi Info software and analyzed by using Statistical Package for Social Science (SPSS) version 20 software. Categorical variables were summarized in frequency, percentage, and chi-square. The data were interpreted by using percentage and chisquare; the result was presented by using tables and graphs. Frequencies and percentages were calculated for all variables related to the study. Binary logistic regression model was used to identify factors associated with knowledge and preventive practice towards CKD. Crude odds ratio (COR) and adjusted odds ratio (AOR) were used to measure the strength of association between dependent and independent variables. In addition, Pearson's correlation between knowledge and practice score was assessed. A $P$ value of less than 0.05 was used to classify statistically significant associated variables with the dependent variables.

\section{Results}

3.1. Sociodemographic Characteristics of the Study Participants. A total of 442 hypertensive patients were asked to participate in the study and 434 completed the questionnaire and included in the study with a response rate of $98.1 \%$. Out of a total of 434 participants, $220(50.7 \%)$ were male. Majority of the participants, 201 (46.3\%), were in the age group $>55$ years, $117(27 \%)$ were unable to read and write, 156 (35.6\%) had DM comorbidity, 290 (66.8\%) were married, $359(82.7 \%)$ were living in urban areas, and 287 (66.1\%) had $<5$-year follow-up (Table 1 ).

3.2. Knowledge of Study Participants. Out of a total of 434 participants, 298 (68.7\%) had good knowledge of CKD with the knowledge mean score of $8.78 \pm 2.80$. Majority of the participants, 267 (61.5\%), responded that they heard of CKD at least once before, 279 (64.3\%) identified the risk factor of CKD, and 415 (95.6\%) knew CKD can be diagnosed and treated. In addition, 372 (85.7\%) were aware of the importance of regular checkups for CKD prevention and early detection, but only 155 (35.7\%) were aware of the effect of drug overdose and/or traditional medicine on CKD (Table 2).

3.3. Preventive Practices of Study Participants. Of the total study participants, $210(48.4 \%)$ had good practice towards $\mathrm{CKD}$ with a mean practice score of $6.58 \pm 1.61$. The majority of the study participants, $379(87.3 \%)$, did not eat wellbalanced meals, 402 (92.6\%) did not exercise regularly, and $360(82.9 \%)$ did not visit health institutions for diagnosis of other disease comorbidities. However, 418 (96.3\%) participants were nonsmokers, 413 (95.2\%) correctly followed the medications, and 408 (94.0\%) were correctly following food restrictions from physicians (Table 3 ).

3.4. Factors Associated with Knowledge of Study Participants. In multivariate logistic regression, educational status, residence, and duration of hypertension were significantly associated with knowledge towards CKD. Accordingly, urban resident study participants were 2.21 times $(\mathrm{AOR}=2.21 ; 95 \%$ CI: $1.09,4.5)$ knowledgeable compared to rural resident participants. In addition, the study participants who attended primary and secondary schools were 18.34 times $(\mathrm{AOR}=18.34 ; 95 \% \mathrm{CI}: 2.1,16.7)$ and 8.6 times $(\mathrm{AOR}=8.6$; 95\% CI: 2.11, 34.99) knowledgeable than those who could not read and write, respectively. In addition, the study participants with a duration of 5 to 10 years of hypertension were 2.14 times knowledgeable ( $\mathrm{AOR}=2.14$; $95 \% \mathrm{CI}: 1.22$, 3.75) compared to participants with fewer than 5 years of hypertension duration (Table 4).

3.5. Factors Associated with Preventive Practice of the Study Participants. In multivariate logistic regression, educational status, residence, and duration of hypertension were significantly associated with level of practice towards CKD. Therefore, urban residents and college and above educational status were 2.27 times ( $\mathrm{AOR}=2.27 ; 95 \% \mathrm{CI}: 1.06,4.83$ ) and 6.26 times $(\mathrm{AOR}=6.26$; 95\% CI: 3.35, 20.37) higher preventive practices compared to rural residents and unable to read and write participants, respectively. In addition, the study participants with a duration of fewer than five years of 
TABle 1: Sociodemographic characteristics of the study participants at Gondar town in 2019.

\begin{tabular}{|c|c|c|c|}
\hline Variable & Categories & Frequency $(n)$ & Percentage (\%) \\
\hline \multirow{4}{*}{ Age (years) } & $<35$ & 40 & 9.2 \\
\hline & $36-45$ & 101 & 23.3 \\
\hline & $46-55$ & 92 & 21.2 \\
\hline & $>55$ & 201 & 46.3 \\
\hline \multirow{2}{*}{ Sex } & Male & 220 & 50.7 \\
\hline & Female & 214 & 49.3 \\
\hline \multirow{4}{*}{ Marital status } & Single & 63 & 14.5 \\
\hline & Divorced & 54 & 12.4 \\
\hline & Married & 290 & 66.8 \\
\hline & Widowed & 27 & 6.2 \\
\hline \multirow{5}{*}{ Educational status } & Unable to read and write & 117 & 27.0 \\
\hline & Able to read and write without formal education & 169 & 38.9 \\
\hline & Primary school & 23 & 5.3 \\
\hline & Secondary school & 41 & 9.4 \\
\hline & College/university and above & 84 & 19.4 \\
\hline \multirow{4}{*}{ Religion } & Orthodox & 353 & 81.3 \\
\hline & Protestant & 20 & 4.6 \\
\hline & Muslim & 60 & 13.6 \\
\hline & Others & 1 & 0.2 \\
\hline \multirow{2}{*}{ Residence } & Urban & 359 & 82.7 \\
\hline & Rural & 75 & 17.3 \\
\hline \multirow{7}{*}{ Occupation } & Private business & 74 & 17.1 \\
\hline & Government employee & 89 & 20.5 \\
\hline & Private employee & 88 & 20.3 \\
\hline & Daily laborer & 53 & 12.2 \\
\hline & Student & 24 & 5.5 \\
\hline & Unemployed & 86 & 19.8 \\
\hline & Others & 20 & 4.6 \\
\hline \multirow{3}{*}{ Duration of hypertension (years) } & Less than 5 & 287 & 66.1 \\
\hline & 5 to 15 & 122 & 28.1 \\
\hline & Above 15 & 25 & 5.7 \\
\hline \multirow{9}{*}{ Disease comorbidities } & Diabetes mellitus & 156 & 35.9 \\
\hline & Stroke & 48 & 11.1 \\
\hline & Asthma & 25 & 5.8 \\
\hline & HIV/AIDS & 3 & 0.7 \\
\hline & Hypercholesterolemia & 4 & 0.9 \\
\hline & Malaria & 23 & 5.3 \\
\hline & Tuberculosis & 12 & 2.8 \\
\hline & Other & 17 & 3.9 \\
\hline & None & 153 & 35.2 \\
\hline
\end{tabular}

TABLE 2: Knowledge assessment towards CKD among hypertensive patients at Gondar town in 2019.

\begin{tabular}{lrr}
\hline Knowledge assessment & Correct response $n$ (\%) & Incorrect response $n$ (\%) \\
\hline Ever heard of CKD & $267(61.5)$ & $167(38.5)$ \\
Risk factors of CKD & $279(64.3)$ & $155(35.7)$ \\
Effect of prolonged use of medications on CKD & $191(44.0)$ & $243(56.0)$ \\
Effect of uncontrolled hypertension on CKD & $244(56.2)$ & $190(43.8)$ \\
Effect of poor glycemic control on CKD & $173(39.9)$ & $261(60.1)$ \\
Effect of early detection of CKD & $168(38.7)$ & $266(61.3)$ \\
Effect of unprescribed traditional drugs on CKD & $155(35.7)$ & $279(64.3)$ \\
CKD can be diagnosed and treated & $415(95.6)$ & $19(4.4)$ \\
Mentioned at least one sign and symptom of CKD & $275(63.4)$ & $159(36.6)$ \\
Effect of CKD on other diseases & $326(75.1)$ & $108(24.9)$ \\
Effect of regular exercise on CKD & $246(56.7)$ & $188(43.3)$ \\
Effect of smoking on CKD & $323(74.4)$ & $111(25.6)$ \\
Effect of regular blood pressure follow-up and control on CKD & $372(85.7)$ & $62(14.3)$ \\
Effect of excessive alcohol drinking on CKD & $378(87.1)$ & $56(12.9)$ \\
\hline
\end{tabular}


TABle 3: Practice assessment towards CKD among hypertensive patients at Gondar town in 2019.

\begin{tabular}{lcc}
\hline Practice assessment & Good $n(\%)$ & Poor $n(\%)$ \\
\hline Balanced diet & $55(12.7)$ & $379(87.3)$ \\
Regular exercise & $32(7.4)$ & $402(92.6)$ \\
Smoke cigarette & $16(3.7)$ & $418(96.3)$ \\
Drink alcohol & $319(73.5)$ & $115(26.5)$ \\
Normal body mass index & $217(50.0)$ & $217(50.0)$ \\
Regular blood pressure checkup & $389(89.6)$ & $45(10.4)$ \\
Take traditional medicine without physician recommendation & $214(49.3)$ & $220(50.7)$ \\
Follow hypertension medications regimen/treatment adherence & $413(95.2)$ & $21(4.8)$ \\
Follow food restrictions by the physicians & $408(94.0)$ & $26(6.0)$ \\
Personal hygiene & $315(72.6)$ & $119(27.4)$ \\
Regular visit to health institutions for diagnosis of CKD & $74(17.1)$ & $360(82.9)$ \\
\hline
\end{tabular}

CKD : chronic kidney disease.

TABLE 4: Bivariate and multivariate analysis of factors associated with knowledge towards CKD.

\begin{tabular}{|c|c|c|c|c|c|c|}
\hline \multirow[b]{2}{*}{ Variables } & \multirow[b]{2}{*}{ Category } & \multicolumn{2}{|c|}{ Knowledge } & \multirow[b]{2}{*}{ COR 95\% CI } & \multirow[b]{2}{*}{ AOR 95\% CI } & \multirow[b]{2}{*}{$P$ value } \\
\hline & & $\begin{array}{l}\text { Good } n \\
(\%)\end{array}$ & $\begin{array}{c}\text { Poor } n \\
(\%)\end{array}$ & & & \\
\hline \multirow[t]{2}{*}{ Sex } & Male & $\begin{array}{c}166 \\
(38.2 \%)\end{array}$ & $54(12.4 \%)$ & 1.00 & 1.00 & \\
\hline & Female & $132(30.4)$ & $82(18.8 \%)$ & $0.524(0.35,0.79)$ & $0.61(0.36,1.01)$ & 0.055 \\
\hline \multirow{5}{*}{ Educational status } & Unable to read and write & $60(13.8 \%)$ & $57(13.1 \%)$ & 1.00 & 1.00 & \\
\hline & $\begin{array}{l}\text { Able to read and write without formal } \\
\text { education }\end{array}$ & $113(26.0)$ & $56(12.9 \%)$ & $1.917(1.18,3.11)$ & $1.29(0.68,2.45)$ & 0.223 \\
\hline & Primary school & $22(5.0 \%)$ & $\begin{array}{c}1.0 \\
(0.23 \%)\end{array}$ & $20.9(2.73,160.20)$ & $18.34(2.1,16.70)$ & $0.008^{*}$ \\
\hline & Secondary school & $38(8.7 \%)$ & $\begin{array}{c}3.0 \\
(0.69 \%)\end{array}$ & $12.03(3.52,41.17)$ & $8.6(2.11,34.99)$ & $0.003^{*}$ \\
\hline & University/college and above & $65(14.9 \%)$ & $19(4.3 \%)$ & $3.25(1.74,6.08)$ & $1.86(0.77,4.50)$ & 0.168 \\
\hline \multirow[b]{2}{*}{ Residence } & Rural & $40(9.2 \%)$ & $35(8.0 \%)$ & 1.00 & 1.00 & \\
\hline & Urban & $\begin{array}{c}258 \\
(59.4 \%)\end{array}$ & $101(23 \%)$ & $2.235(1.34,3.72)$ & $2.21(1.09,4.50)$ & $0.028^{*}$ \\
\hline \multirow{3}{*}{$\begin{array}{l}\text { Hypertension duration } \\
\text { (years) }\end{array}$} & $<5$ & $\begin{array}{c}186 \\
(42.8 \%)\end{array}$ & $101(23 \%)$ & 1.00 & 1.00 & \\
\hline & $5-15$ & $92(21.1 \%)$ & $30(6.9 \%)$ & $1.66(1.03,2.69)$ & $2.14(1.22,3.75)$ & $0.008^{*}$ \\
\hline & $>15$ & $20(4.6 \%)$ & $5.0(1.1 \%)$ & $2.17(0.79,5.96)$ & $3.02(0.97,9.40)$ & 0.056 \\
\hline \multirow{4}{*}{ Age group (years) } & $<35$ & $24(5.5 \%)$ & $16(3.6 \%)$ & 1.00 & 1.00 & \\
\hline & $35-45$ & $71(16.3 \%)$ & $31(7.1 \%)$ & $1.53(0.71,3.27)$ & $1.21(0.5,2.90)$ & 0.666 \\
\hline & $45-55$ & $64(14.7 \%)$ & $28(6.4 \%)$ & $1.524(0.7,3.30)$ & $1.42(0.58,3.48)$ & 0.442 \\
\hline & $>55$ & $139(32 \%)$ & $61(14 \%)$ & $1.53(0.75,3.06)$ & $1.55(0.68,3.50)$ & 0.291 \\
\hline
\end{tabular}

$\mathrm{AOR}=$ adjusted odds ratio, $\mathrm{COR}=$ crude odds ratio, $\mathrm{CI}=$ confidence interval, ${ }^{*}=P<0.05$ significant association.

hypertension have an $81 \%$ higher preventive practice than participants with a duration of more than 15 years of hypertension (Table 5).

\section{Discussion}

Of the 434 participants, 298 (68.7\%) had good knowledge of CKD. This finding was higher than the study done in Nigeria (27.1\%) [12], Malaysia (26.3\%) [15] and (30.1\%) [16], and Palestine $(61.8 \%)$. The difference may be because the study participants were institution-based and had a better access to health education than the general community. However, this finding was lower compared to the study done in Jordan, where $80.24 \%$ were knowledgeable towards CKD [17]. This might be due to the difference in sample size and source population of the study.
More than half of the participants 267 (61.5\%) heard of CKD at least once before. This finding was slightly lower than the study done in Malaysia (69.5\%) [15]. The difference may be due to difference in access to health education of the participant. In the current study, 275 (63.4\%) correctly answered the signs and symptoms of CKD; this finding was higher than the Jordan study in which about half of the participants 370 (50\%) had incorrect information about CKD signs and symptoms [17]. The possible reason for the variation might be attributed to the differences in sociodemographic and access to CKD learning opportunities.

In the current study, 244 (56.2\%) of the participants were aware of the effect of uncontrolled hypertension on CKD, which was higher than the study in Tanzania, where only $17 \%$ were aware that high blood pressure could cause CKD [18]. This may be due to differences in access to health 
TABLE 5: Bivariate and multivariate analysis of factors associated with preventive practice towards CKD.

\begin{tabular}{|c|c|c|c|c|c|c|}
\hline \multirow{2}{*}{ Variables } & \multirow{2}{*}{ Category } & \multicolumn{2}{|c|}{ Practice } & \multirow{2}{*}{ COR 95\% CI } & \multirow{2}{*}{ AOR 95\% CI } & \multirow{2}{*}{$P$ value } \\
\hline & & Good $n(\%)$ & Poor $n(\%)$ & & & \\
\hline \multirow{2}{*}{ Sex } & Male & $91(20.9 \%)$ & $129(29.7 \%)$ & 1.00 & 1.00 & \\
\hline & Female & $119(27.4 \%)$ & $95(21.8 \%)$ & $1.78(1.21,2.60)$ & $1.65(0.99,2.71)$ & 0.05 \\
\hline \multirow{4}{*}{ Age } & $<35$ years & $19(4.3 \%)$ & $21(4.8 \%)$ & 1.00 & 1.00 & \\
\hline & $35-45$ years & $48(11.0 \%)$ & $54(12.4 \%)$ & $0.98(0.47,2.04)$ & $0.79(0.325,1.93)$ & 0.609 \\
\hline & $45-55$ years & $41(9.4 \%)$ & $51(11.7 \%)$ & $0.89(0.42,1.87)$ & $0.68(0.27,1.69)$ & 0.408 \\
\hline & $>55$ years & $102(23.5 \%)$ & $98(22.5 \%)$ & $1.15(0.58,2.27)$ & $0.89(0.39,2.05)$ & 0.784 \\
\hline \multirow{5}{*}{ Educational status } & Illiterates & $49(11.2 \%)$ & $68(15.6 \%)$ & 1.00 & 1.00 & \\
\hline & Able read and write & $72(16.5 \%)$ & $97(22.3 \%)$ & $1.03(0.64,1.66)$ & $1.51(0.77,2.96)$ & 0.230 \\
\hline & Primary school & $8(1.8 \%)$ & $15(3.4 \%)$ & $0.74(0.29,1.88)$ & $1.46(0.46,4.61)$ & 0.523 \\
\hline & Secondary school & $18(4.1 \%)$ & $23(5.2 \%)$ & $1.086(0.53,2.23)$ & $2.47(0.91,6.76)$ & 0.077 \\
\hline & University/college and above & $63(14.5 \%)$ & $21(4.8 \%)$ & $4.16(2.25,7.70)$ & $8.26(3.35,20.37)$ & $<0.001 *$ \\
\hline \multirow{4}{*}{ Marital status } & Married & $145(33.4)$ & $145(33.4 \%)$ & 1.00 & 1.00 & \\
\hline & Divorced & $32(7.3 \%)$ & $22(5.0 \%)$ & $1.45(0.81,2.62)$ & $1.47(0.675,3.20)$ & 0.332 \\
\hline & Widowed & $9(2.0 \%)$ & $18(4.1 \%)$ & $0.50(0.22,1.15)$ & $0.30(0.104,1.01)$ & 0.058 \\
\hline & Single & $24(5.5 \%)$ & $39(8.9 \%)$ & $0.61(0.35,1.07)$ & $0.55(0.26,1.16)$ & 0.118 \\
\hline \multirow{2}{*}{ Residence } & Rural & $18(4.1 \%)$ & $57(13.1 \%)$ & 1.00 & 1.00 & \\
\hline & Urban & $192(44.2 \%)$ & $167(38.4 \%)$ & $3.64(2.06,6.43)$ & $2.27(1.06,4.83)$ & $0.034^{*}$ \\
\hline \multirow{3}{*}{ Hypertension duration (years) } & $<5$ years & $132(30.4 \%)$ & $155(35.5 \%)$ & 1.00 & 1.00 & \\
\hline & $5-15$ years & $70(16.1 \%)$ & $52(11.9 \%)$ & $1.58(1.03,2.42)$ & $1.41(0.84,2.38)$ & 0.197 \\
\hline & $>15$ years & $8(1.8 \%)$ & $17(3.9 \%)$ & $0.55(0.21,1.32)$ & $0.19(0.065,0.58)$ & $0.003 *$ \\
\hline
\end{tabular}

$\mathrm{AOR}=$ adjusted odds ratio, $\mathrm{COR}=$ crude odds ratio, $\mathrm{CI}=$ confidence interval ${ }^{*}=P<0.05$ significant association.

education. In addition, the study found that $244(56.2 \%)$ were aware of uncontrolled hypertension on CKD, which was higher than the study conducted in Iran that only $14.4 \%$ of the respondents were aware of the uncontrolled hypertension as very likely to result in CKD [19]. In addition, 279 (64.3\%) of participants responded correctly to the risk factors of CKD and this was higher in the Jordan study, with more than $50 \%$ of the participants identifying the risk factors of CKD [17]. This may be due to differences in the study population since because our study participants were on medical follow-up and had a health education program, Iran and Jordan's studies were community based.

Of the study participants, $48.4 \%$ had good practice towards CKD. This finding was lower compared to the studies conducted in a tertiary teaching hospital, Malaysia, which found good practice scores in more than $88.3 \%$ of participants [16]. This may be due to difference in educational status, economic status, and health education practice about CKD. Out of a total of participants, $12.7 \%$ take well-balanced diet, which was lower than the Jordan study, 60.6\% [17]. This may be due to differences in the economic status of study participants. However, $95.2 \%$ of the participants adhered to medication, which was higher than the Jordan study of $62.7 \%$ [17]. This may be due to the fact that the current study's participants have been included from the health institution and that there are regular follow-up and health education opportunities for the patients.

In the multivariate logistic analysis, knowledge score was significantly associated with the educational status of our study participants; this was similar to the study in Tanzania [18] and Jordan [17]. This was because participants who had higher educational status had more knowledge about hypertension, its risk, and ways to prevent its adverse effect. In addition, our study showed that there was no significant association between age and knowledge score, which varied from the study done in Brazil [20]. This may be due to disparity in sociodemographic characteristics of the study participants.

In multivariate logistic regression, educational status and duration of hypertension were statistically significantly associated with a higher practice score in multivariate logistic regression. This finding was consistent with the study done in Palestine [14]. This may be due to the fact that participants with higher education levels have access to information from different journals and information sources. However, we found that there was no significant association between age and practice. This finding was different from the study conducted in Jordan, which showed that being of older age is associated with a better practice score [17]. This may be due to differences in sample size and sociodemographic characteristics of the study participants.

4.1. Limitation. The response of the participants may be affected by the interviewer's bias and the findings of this study cannot be generalized to the other city populations of the country due to the difference in sociodemographic characteristics.

\section{Conclusion}

More than half of the participants had good knowledge of CKD. However, fewer than half of the participants had a good preventive practice score towards the CKD. In multivariate logistic regression, educational status, residence, and duration of hypertension were significantly associated 
with knowledge and practice score of participants towards CKD. Therefore, additional effort should be made by responsible organizations to increase the community's awareness and preventive practice towards CKD.

\section{Abbreviations}

AOR: Adjusted odds ratio

BP: $\quad$ Blood pressure

CI: Confidence interval

CKD: Chronic kidney disease

COR: Crude odds ratio

DM: Diabetes mellitus

ESRD: End-stage renal disease

GBD: Global Burden of Disease

GFR: Glomerular filtration rate

SPSS: Statistical Package for Social Science.

\section{Data Availability}

Most of the data generated or analyzed during this study are included in this published article, and additional files will be available from the corresponding author upon request.

\section{Ethical Approval}

The study was approved by the ethical clearance committee of Biomedical and Laboratory Science of the University of Gondar.

\section{Consent}

Each participant was informed in detail and his/her written consent was obtained before the data collection.

\section{Conflicts of Interest}

The authors declare that they have no conflicts of interest.

\section{Authors' Contributions}

Daniel Asmelash conceptualized and designed the study. Alebachew Fasil, Daniel Asmelash, Elias Chane, Getahun Desalegn, Getie lake aynalem, and Sewmalet Assefa supervised, collected data, analyzed, interpreted, and the drafted the manuscript. All the authors read and approved the final manuscript.

\section{Acknowledgments}

The authors would like to thank the study participants for their voluntary participation in the study.

\section{Supplementary Materials}

English version questionnaires. Part 1: sociodemographic information of participants. Part 2: knowledge assessment questionnaires. Part 3: questionnaires to assess practice. (Supplementary Materials)

\section{References}

[1] A. S. Levey, J. Coresh, E. Balk et al., "National Kidney Foundation practice guidelines for chronic kidney disease: evaluation, classification, and stratification," Annals of Internal Medicine, vol. 139, no. 2, pp. 137-147, 2003.

[2] R. A. Hamer and A. M. E. Nahas, "The burden of chronic kidney disease," Bmj, vol. 332, no. 7541, pp. 563-564, 2006.

[3] C. O. Alebiosu and O. E. Ayodele, "The global burden of chronic kidney disease and the way forward," Ethnicity \&amp; Disease, vol. 15, no. 3, pp. 418-23, 2005.

[4] R. J. Cherono, "The prevalence and risk factors for chronic kidney diseases in kericho county, Kenya," International Journal of Nursing, vol. 4, no. 2, p. 16, 2017.

[5] K. T. Mills, Y. Xu, W. Zhang et al., "A systematic analysis of worldwide population-based data on the global burden of chronic kidney disease in 2010," Kidney International, vol. 88, no. 5, pp. 950-957, 2015.

[6] G. Abraham, K. N. Arun, N. Gopalakrishnan et al., "Management of hypertension in chronic kidney disease: consensus statement by an expert panel of Indian nephrologists," Journal of The Association of Physicians of India, vol. 1, no. 2, pp. 6-21, 2017.

[7] Q.-L. Zhang and D. Rothenbacher, "Prevalence of chronic kidney disease in population-based studies: systematic review," BMC Public Health, vol. 8, no. 1, p. 117, 2008.

[8] N. Alencar de Pinho, R. de Cássia Burgos de Oliveira, and A. M. G. Pierin, "Hypertensive patients with and without kidney disease: assessment of risk factors," Journal of Nursing, vol. 49, no. esp, p. 8, 2015.

[9] G. L. Bakris and E. Ritz, The Message for World Kidney Day 2009: Hypertension and Kidney Disease: A Marriage that Should Be Prevented, Oxford University Press, Oxford, UK, 2009.

[10] V. Jha, G. Garcia-Garcia, K. Iseki et al., "Chronic kidney disease: global dimension and perspectives," The Lancet, vol. 382, no. 9888, pp. 260-272, 2013.

[11] M. Molla, "Systematic reviews of prevalence and associated factors of hypertension in Ethiopia: finding the evidence," Science Journal of Public Health, vol. 3, no. 4, pp. 514-519, 2015.

[12] R. Oluyombo, O. Ayodele, P. Akinwusi et al., "Awareness, knowledge and perception of chronic kidney disease in a rural community of South-West Nigeria," Nigerian Journal of Clinical Practice, vol. 19, no. 2, pp. 161-169, 2016.

[13] D. M. Yusoff, J. Yusof, and Y. C. Kueh, "Knowledge, attitude and practices of the risk for chronic kidney disease among patients in a tertiary teaching hospital," The Malaysian Journal of Nursing, vol. 8, no. 2, pp. 3-11, 2016.

[14] H. H. Sa'adeh, R. N. Darwazeh, A. A. Khalil, and S. H. Zyoud, "Knowledge, attitudes and practices of hypertensive patients towards prevention and early detection of chronic kidney disease: a cross sectional study from Palestine," Clinical Hypertension, vol. 24, p. 6, 2018.

[15] Y. Chiun, S. Zhong, and K. S. Goh, "Cross-sectional study on knowledge of chronic kidney disease among medical outpatient clinic patients," Medical Journal of Malaysia, vol. 71, no. 3, p. 6, 2016.

[16] D. M. Yusoff and Y. C. Kueh, "Knowledge, attitude and practice of the risk for CKD among patients in a tertiary teaching hospital the malaysian," Journal of Nursing, vol. 8, no. 2, p. 9, 2016.

[17] A. Khalil and M. Abdalrahim, "Knowledge, attitudes, and practices towards prevention and early detection of chronic 
kidney disease," International Nursing Review, vol. 61, no. 2, pp. 237-245, 2014.

[18] J. W. Stanifer, E. L. Turner, J. R. Egger et al., "Knowledge, attitudes, and practices associated with chronic kidney disease in northern Tanzania: a community-based study," PloS One, vol. 11, no. 6, Article ID e0156336, 2016.

[19] P. Roomizadeh, D. Taheri, A. Abedini et al., "Limited knowledge of chronic kidney disease and its main risk factors among Iranian community: an appeal for promoting national public health education programs," International Journal of Health Policy and Management, vol. 2, no. 4, pp. 161-166, 2014.

[20] N. Alencar de Pinho, G. Vieira da Silva, and A. M. G. Pierin, "Prevalence and factors associated with chronic kidney disease in patients seen at a university hospital," Jornal brasileiro de nefrologia: 'orgao oficial de Sociedades Brasileira e LatinoAmericana de Nefrologia, vol. 37, no. 1, p. 7, 2015. 